
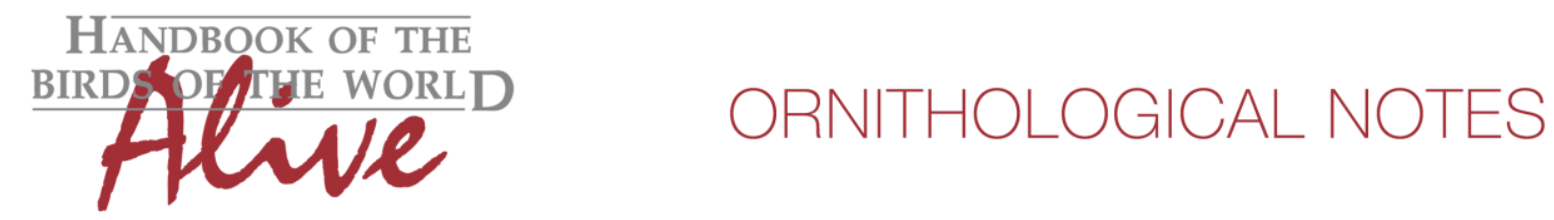

\title{
Notes on the vocalizations of Kungwe Apalis Apalis argentea
}

Peter Boesman

In the following text, I briefly analyze and compare the voice of Kungwe Apalis Apalis argentea with the closely related Buff-throated Apalis Apalis rufogularis. I also try to quantify the extent of any vocal differences using the criteria proposed by Tobias et al. (2010) as a basis for taxonomic review. I have made use of sound recordings available online at Xenocanto $(\mathrm{XC})$ and the Macaulay Library $(\mathrm{ML})$, and several unpublished recordings.

Species status of Apalis argentea, which includes two taxa (nominate and eidos) is controversial. Several sources (Dowsett-Lemaire \& Dowsett 1990, Turner \& Pearson 2015, Mills et al. 2016) have argued to treat argentea and eidos as races of $A$. rufogularis. However, del Hoyo \& Collar (2016) listed several reasons to retain species status pending further information including fuller vocal sampling.

While all sources recommending a lump indicate that the voice of Kungwe Apalis does not differ from Buff-throated Apalis, this is presumably based only on the vocal comparison by Dowsett-Lemaire \& Dowsett (1990).

Recordings of $A$. argentea remain very scarce, I have recently located more recordings than the single song described as 'stronger, less stridulating' than A. rufogularis (del Hoyo \& Collar 2016), which led to a tentative score of 3 using Tobias criteria.

Songs of many Apalis species sound very similar, all typically repeating at regular pace a note or note combination, the latter often showing much variation within a single species. It is thus not always easy to find species-specific features. Another typical feature is duetting, in many cases the singing male is joined by the female, either in asynchronous or synchronous duet. Besides the song and duet, a number of other vocalizations exist, some of which include elements of the typical song.

In the following I illustrate song with several sonograms per taxon and we provide some measurements of basic sound parameters to allow quantification of vocal differences. 

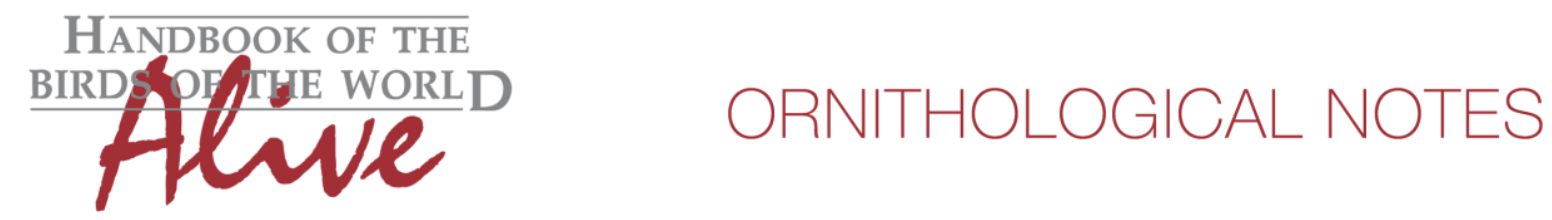

\section{Kungwe Apalis}

\section{$\underline{\text { nominate }}$}

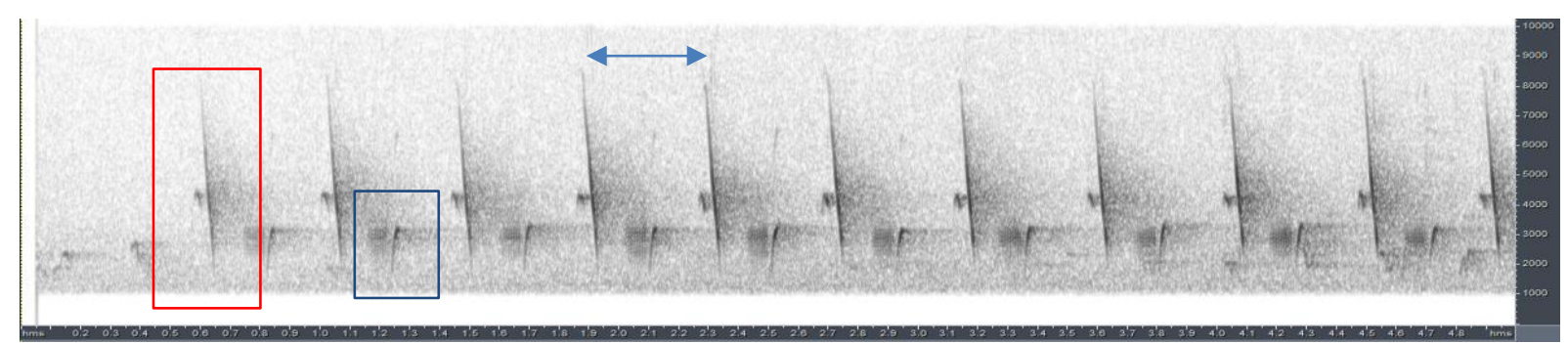

XC83842 (Sitebe, W Tanzania, D. Moyer)

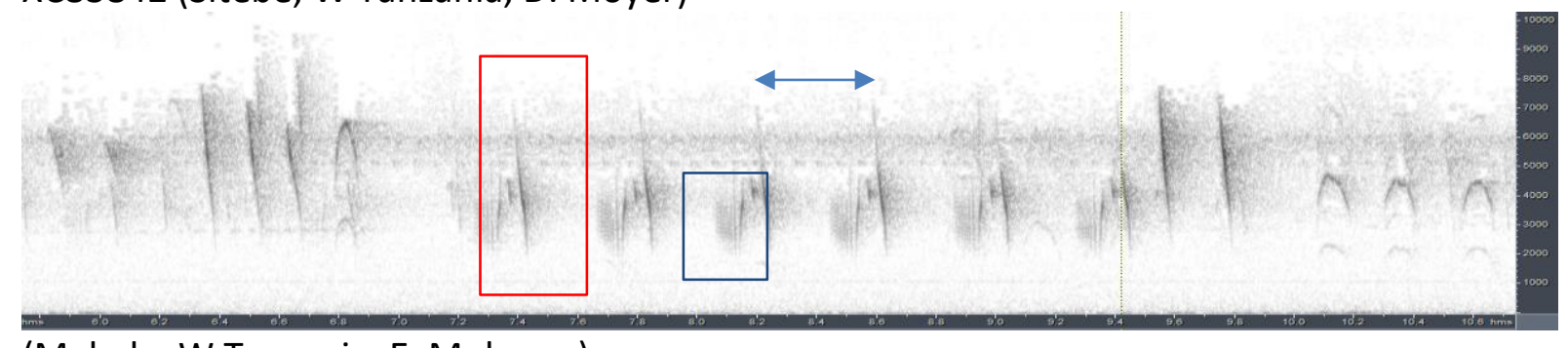

(Mahale, W Tanzania, E. Mulungu)

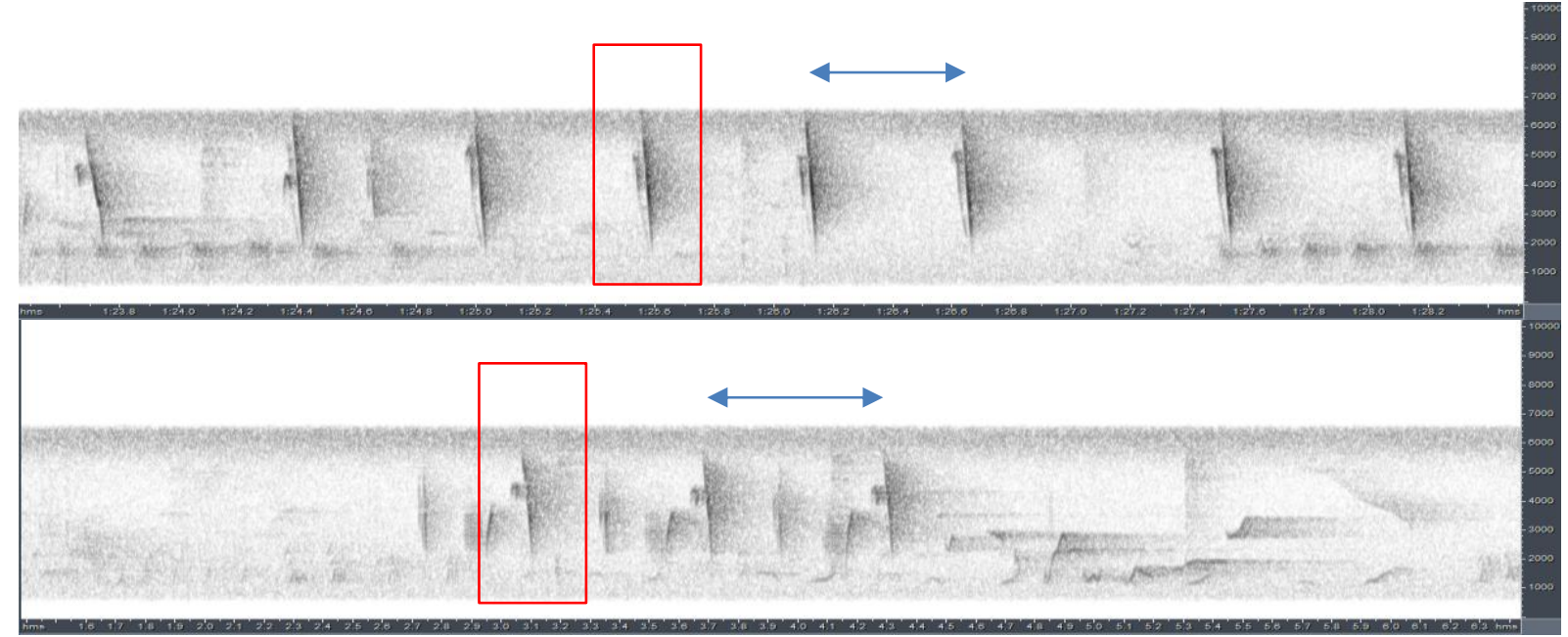

(Ntakata, W Tanzania, D. Moyer)

Typical song is a strident double note that is repeated. The double note (indicated by a red rectangle in the above sonograms) always appears to consist of a very short note with narrow bandwidth followed immediately by a sharply downslurred note with very large bandwidth (sounding like "tsi").

This double note is either repeated at regular pace or alternated with lower-pitched grating notes (blue rectangle; it is unclear whether this is actually a duet with the female), e.g. "tsigrr-tsi-grr-tsi-grr...".

Sometimes the song consists of three parts (last sonogram) or even more 'complex' structures can be noted. 


\section{HANDBOOK OF THE BIRDSPF THE WORLD Alve}

\section{ORNITHOLOGICAL NOTES}

$\underline{\text { eidos }}$
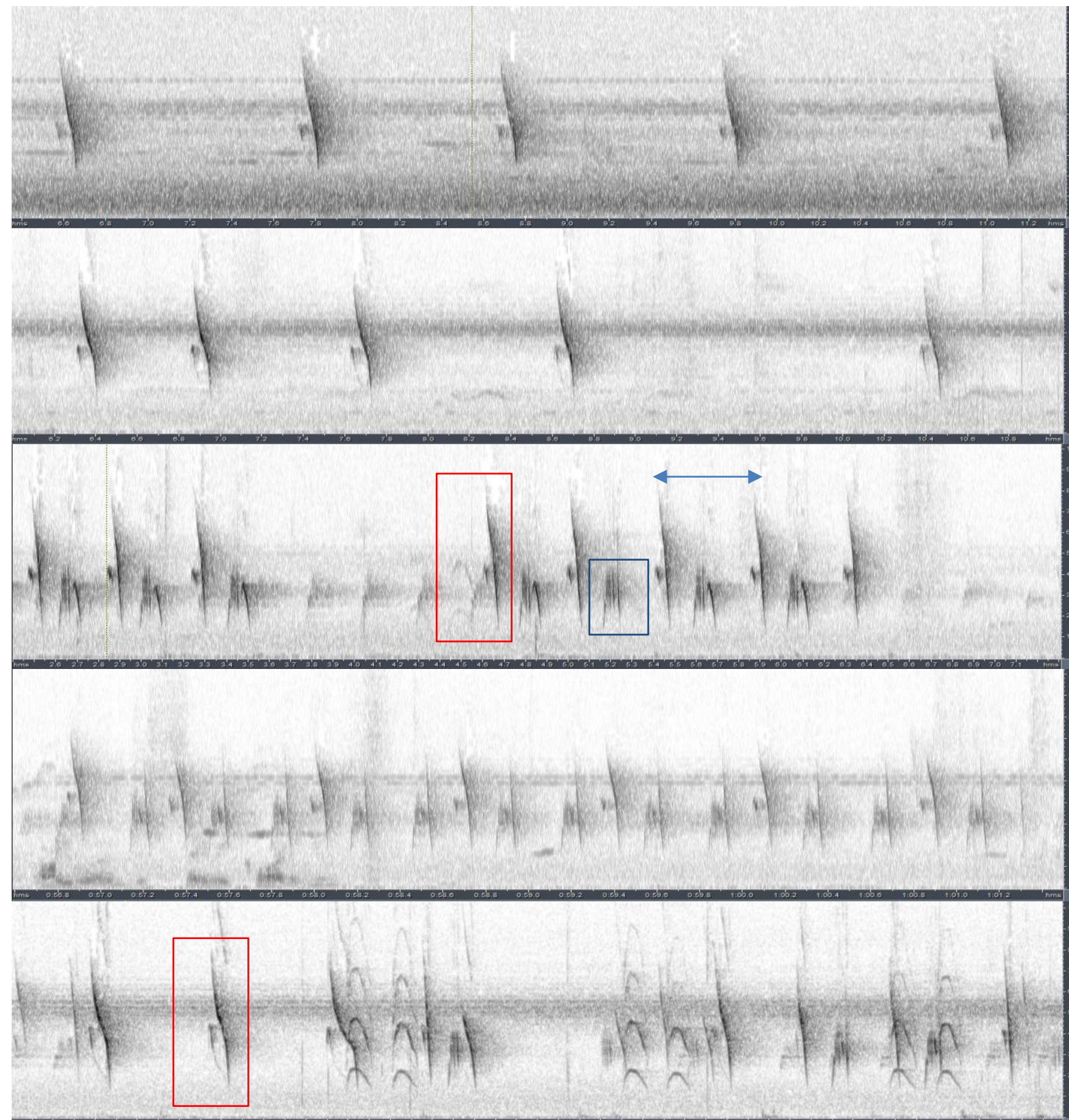

All above sonograms: (Nyungwe, Rwanda, from three different years, M. Mills)

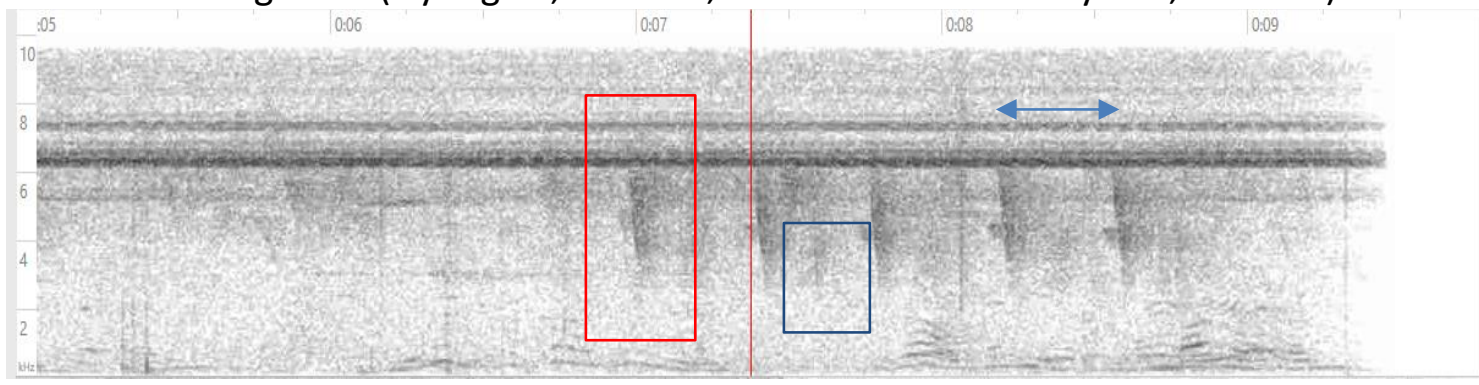

ML64628621 (Nyungwe, Rwanda, R. Treves) 


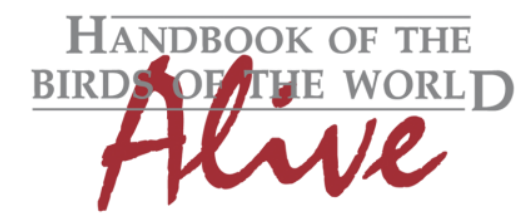

\section{ORNITHOLOGICAL NOTES}

Voice of taxon eidos also has the vocal features described above for argentea. The first two sonograms are of repeated "tsi" notes, the third is a typical "tsi-grr-tsi-grr-tsi-grr..." (duet?) example, the fourth and fifth are examples of more complex structures in which several patterns are mixed (possibly by excited birds, exact circumstances and use of playback unknown). The omission of the typical "tsi" note out of a "2 or 3 part structured song" leads to an alternative song type as described by Dowsett-Lemaire \& Dowsett (1990), which then becomes very similar to the voice of $A$. rufogularis (see below) (unclear if this is then, e.g., the female singing alone) as illustrated in the following sonogram:

(Nyungwe, Rwanda, M. Mills)

\section{To be compared with:}

Buff-throated Apalis Apalis rufogularis (below I used only examples from Kenya and Uganda, corresponding to the geographically closest races nigrescens and kigezi):

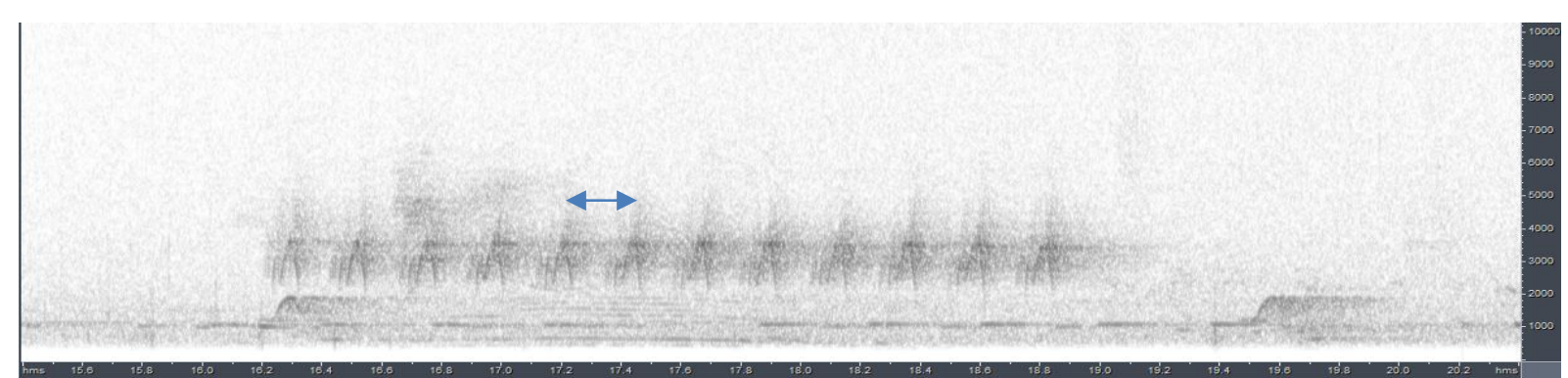

XC363896 (Kenya, J. Bradley)

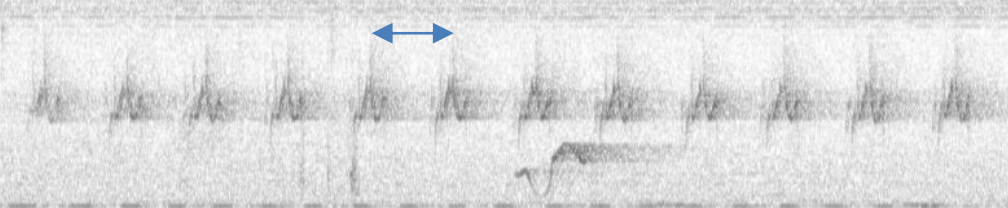

XC396384 (Kenya, J. Bradley) 


\section{HANDBOOK OF THE \\ BIRD S PF,THE WORLD \\ Alve}

\section{ORNITHOLOGICAL NOTES}

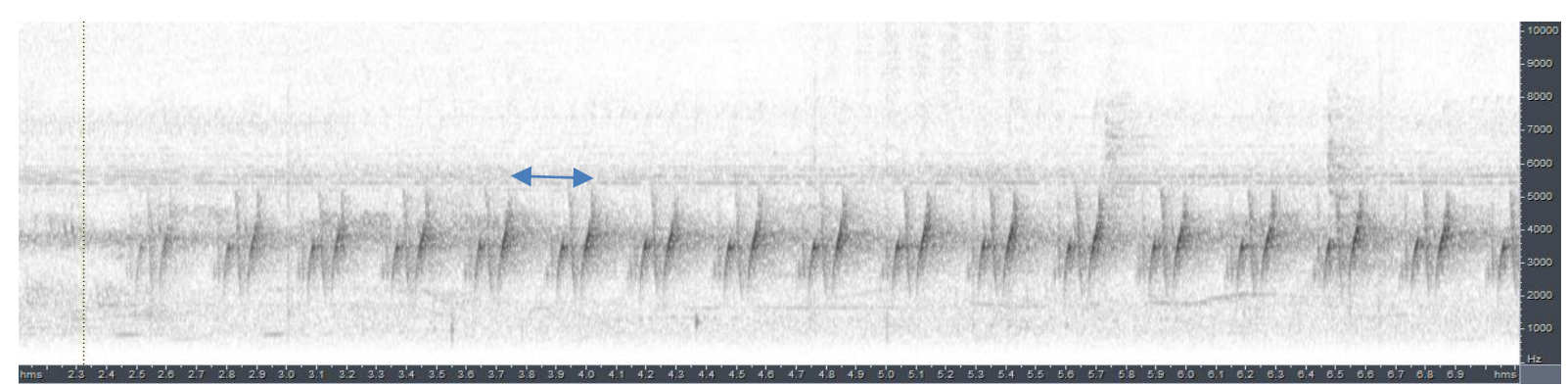

XC136299 (Uganda, J. Engel)

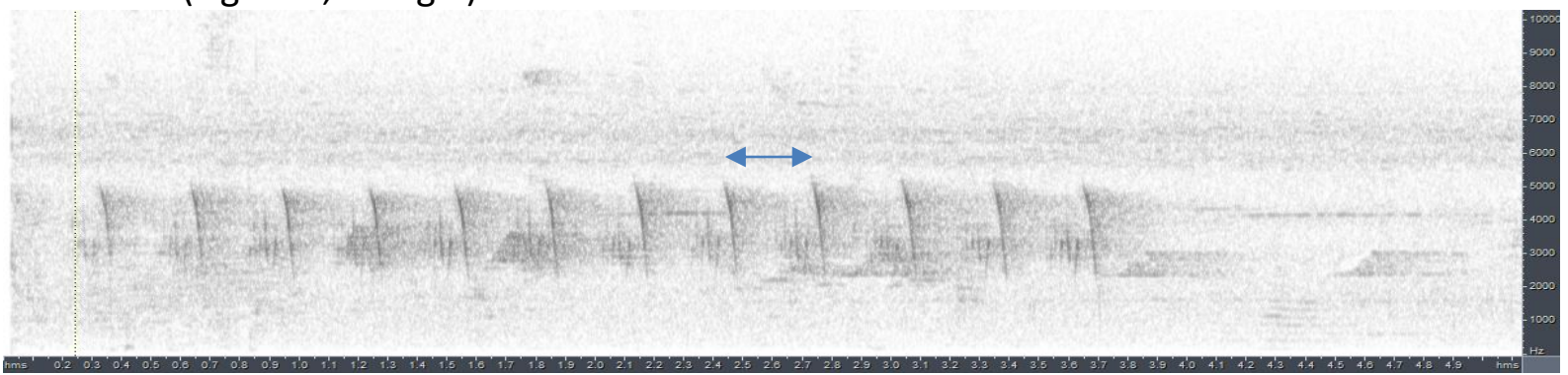

XC283014 (Uganda, M. St Michel)

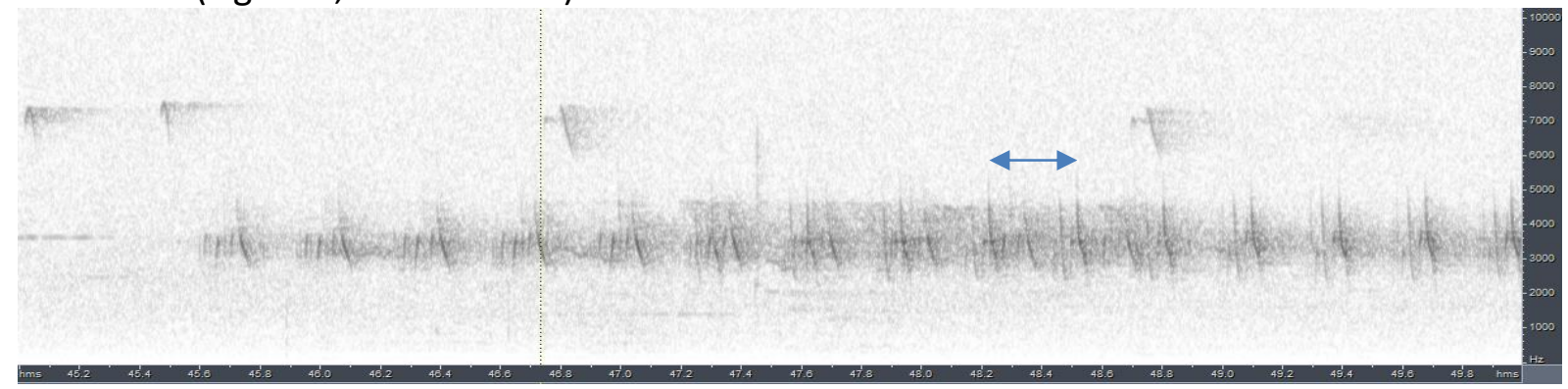

XC290243 (Uganda, M. St Michel)

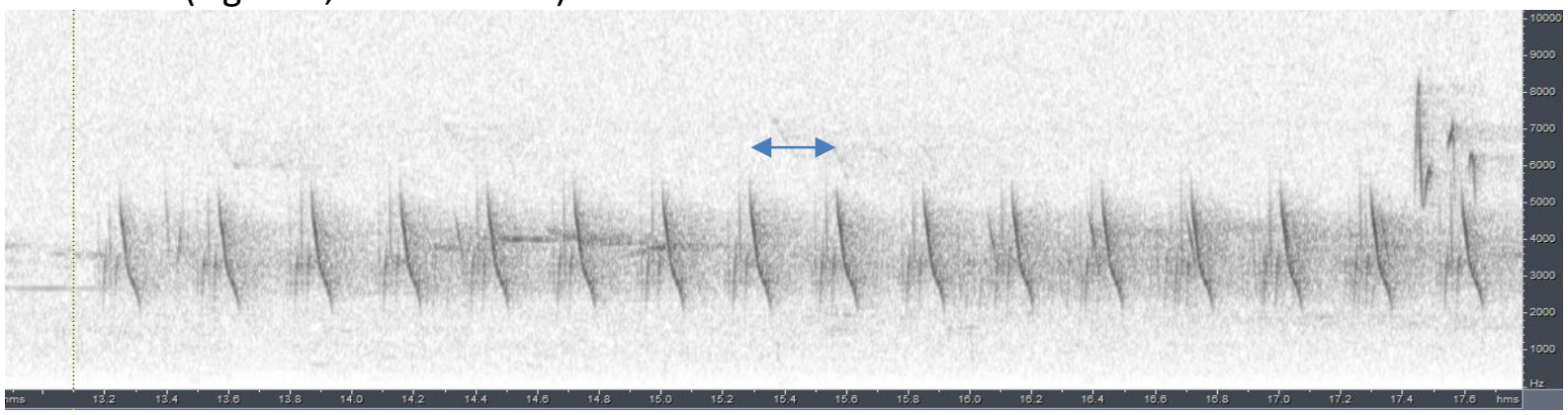

XC295702 (Uganda, M. St Michel)

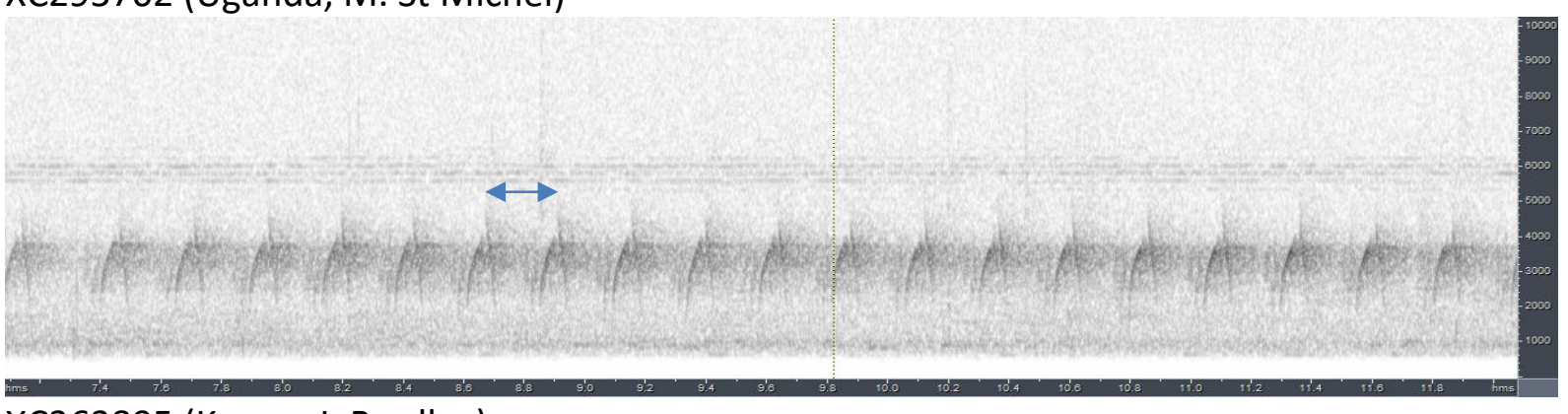

XC363895 (Kenya, J. Bradley)

Song of $A$. rufogularis consists of a repeated fairly complex 'note' with upslurred and/or downslurred elements, which is quite variable (but none like the typical described "tsi" note 


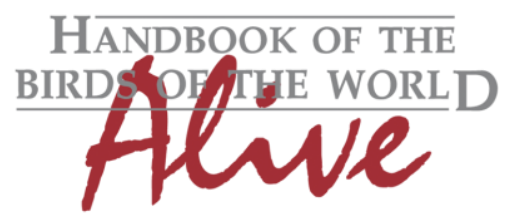

\section{ORNITHOLOGICAL NOTES}

for argentea). Typically sounds like a fast "plip-plip-plip-plip..." or "pirrip-pirrip-pirrip..." lacking the more grating sounds of argentea. At first sight, frequency range seems to be smaller on average, max. frequency lower and pace distinctly higher (see below)

For further comparison, I give some examples of another Apalis, which occurs at least in part sympatrically with eidos and rufogularis:

Grey Apalis Apalis cinerea (all of nominate):

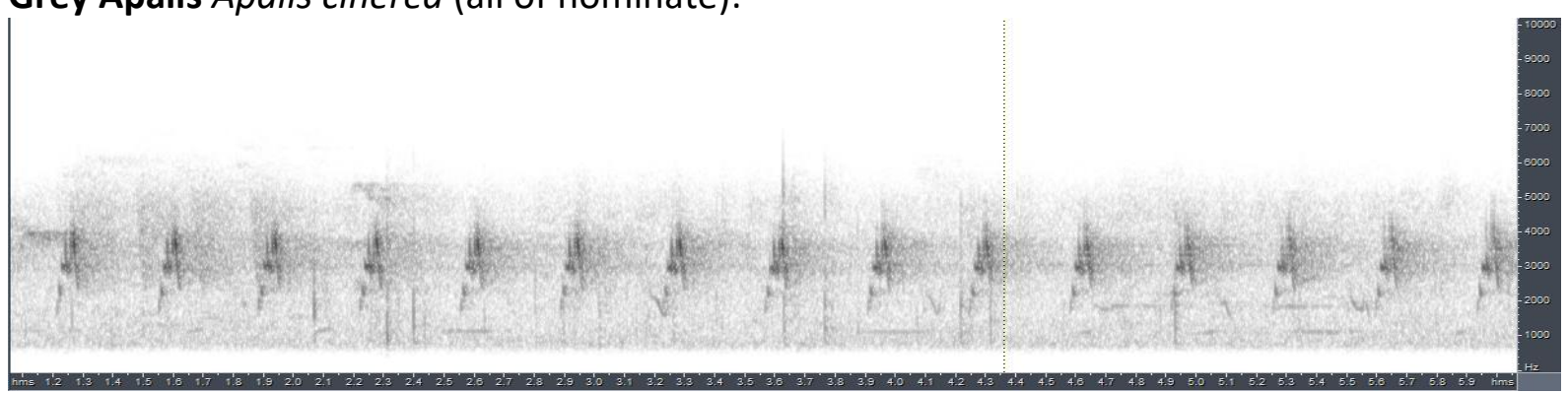

XC289554 (Kenya J. Bradley)

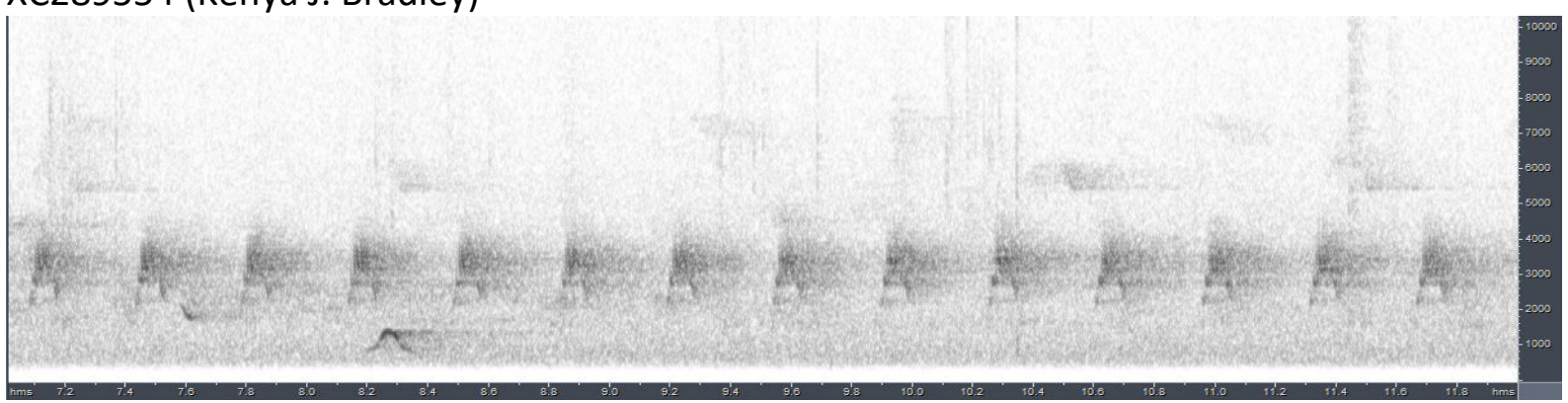

XC429117 (Kenya J. Bradley)

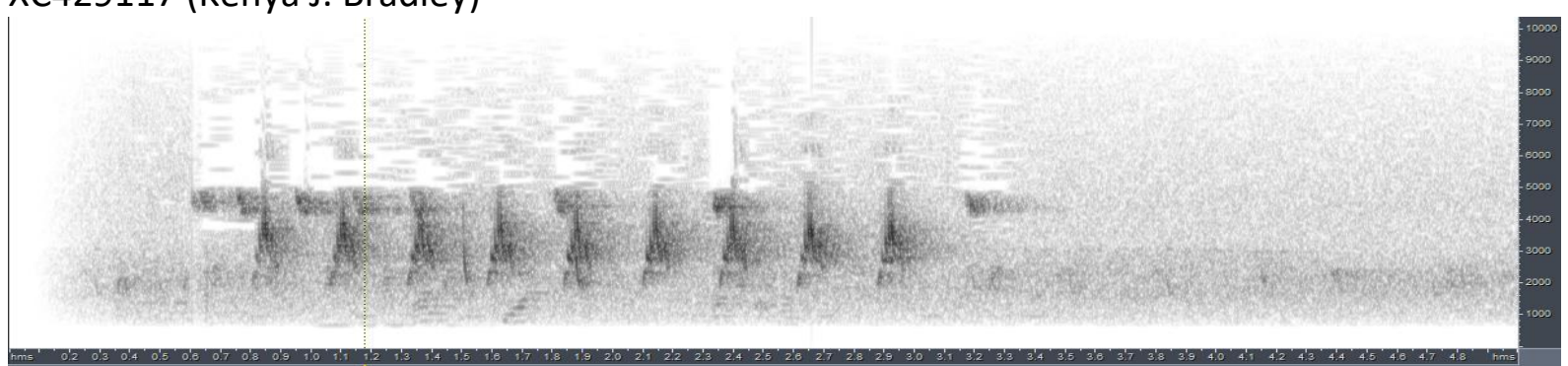

XC101172 (Kenya, J. Bradley)

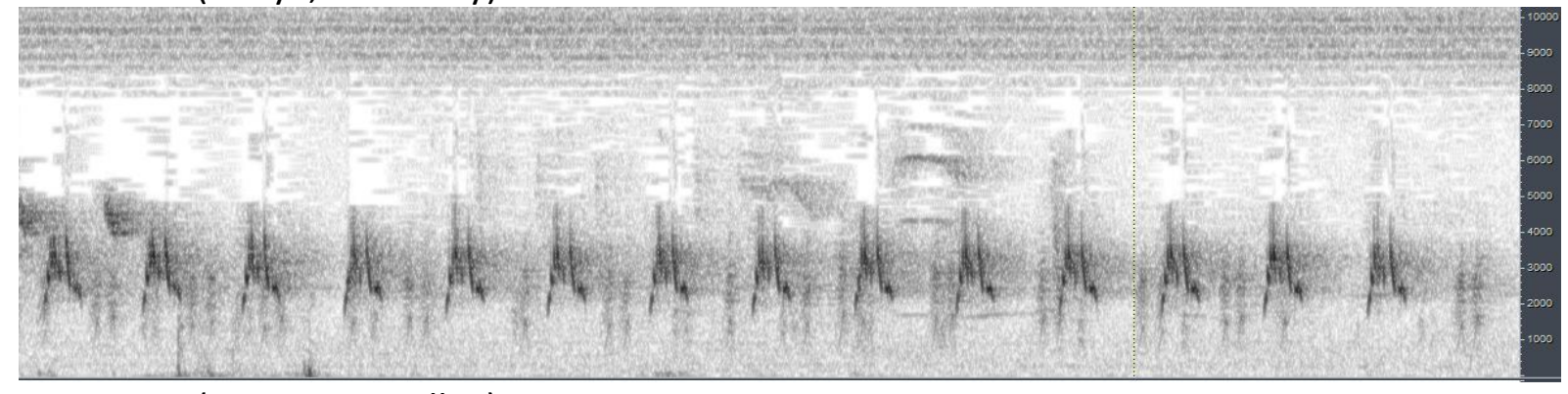

XC107408 (Kenya, J. Bradley)

Song is again a repeated complex 'note', which typically has an upslurred component followed by a downslurred component, giving its typical "pit-pit-pit..." (pace slightly slower than Buff-throated Apalis). 

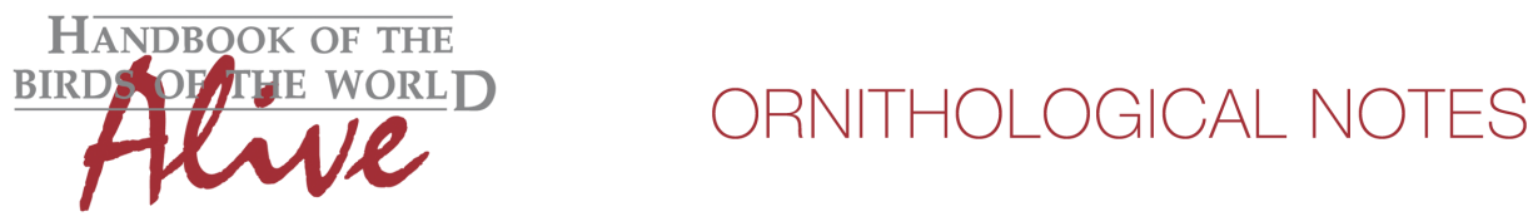

While I don't analyze further this particular species, it is clear from these examples that indeed many Apalis songs show similarities between species, even in the case of (partially) sympatric species!

\section{Some measurements of basic sound parameters of typical songs:}

$\begin{array}{llll} & \begin{array}{l}\text { argentea } \\ (n=4)\end{array} & \begin{array}{l}\text { eidos } \\ (n=6)\end{array} & \begin{array}{l}\text { nigrescens } \\ (n=8)\end{array} \\ \text { Max. freq. repeated note } & 6.0-8.4 \mathrm{kHz} & 6.0-8.0 \mathrm{kHz} & 4.5-5.8 \mathrm{kHz} \\ \text { Max. freq. range (bandwidth) } & 4.0-6.5 \mathrm{kHz} & 5.0-7.0 \mathrm{kHz} & 2.0-3.5 \mathrm{kHz} \\ \text { Pace (notes/s) } & 1.7-2.4 & 1.0-2.6 & 3.0-4.0\end{array}$

These measurements clearly confirm that typical songs of argentea and eidos include notes with a higher max. frequency, a higher bandwidth and the note series are given at a slower pace.

\section{Discussion}

Rather surprisingly, it would thus seem that the voices of both argentea and eidos are actually quite different from Buff-throated Apalis, and (at least in the case of the commonest song type) can easily be identified on a sonogram!

This seems to contradict the conclusions given in Dowsett-Lemaire \& Dowsett (1990). In their study, sonograms were compared, but apparently only qualitatively without measurements (this may appear strange now, but 30 years ago sonograms could not be simply shown on a PC screen). When we look at the sonograms depicted in the paper (see below), the quantitative differences mentioned above are in fact perfectly visible despite being high-contrast black/white sonograms: fig. a-d (eidos, Nyungwe) have clearly max. freq. of c. $6-7 \mathrm{kHz}$ while fig. e-g (e-f: rufogularis nigrescens, g: nominate rufogularis) have c. 5$6 \mathrm{kHz}$, and the first second of sonograms fig. a-d clearly have only 1.8-2.7phrases/s vs. 2.93.6 phrases/s in fig. e-g) while the unique "tsi" call is also visible for eidos. 

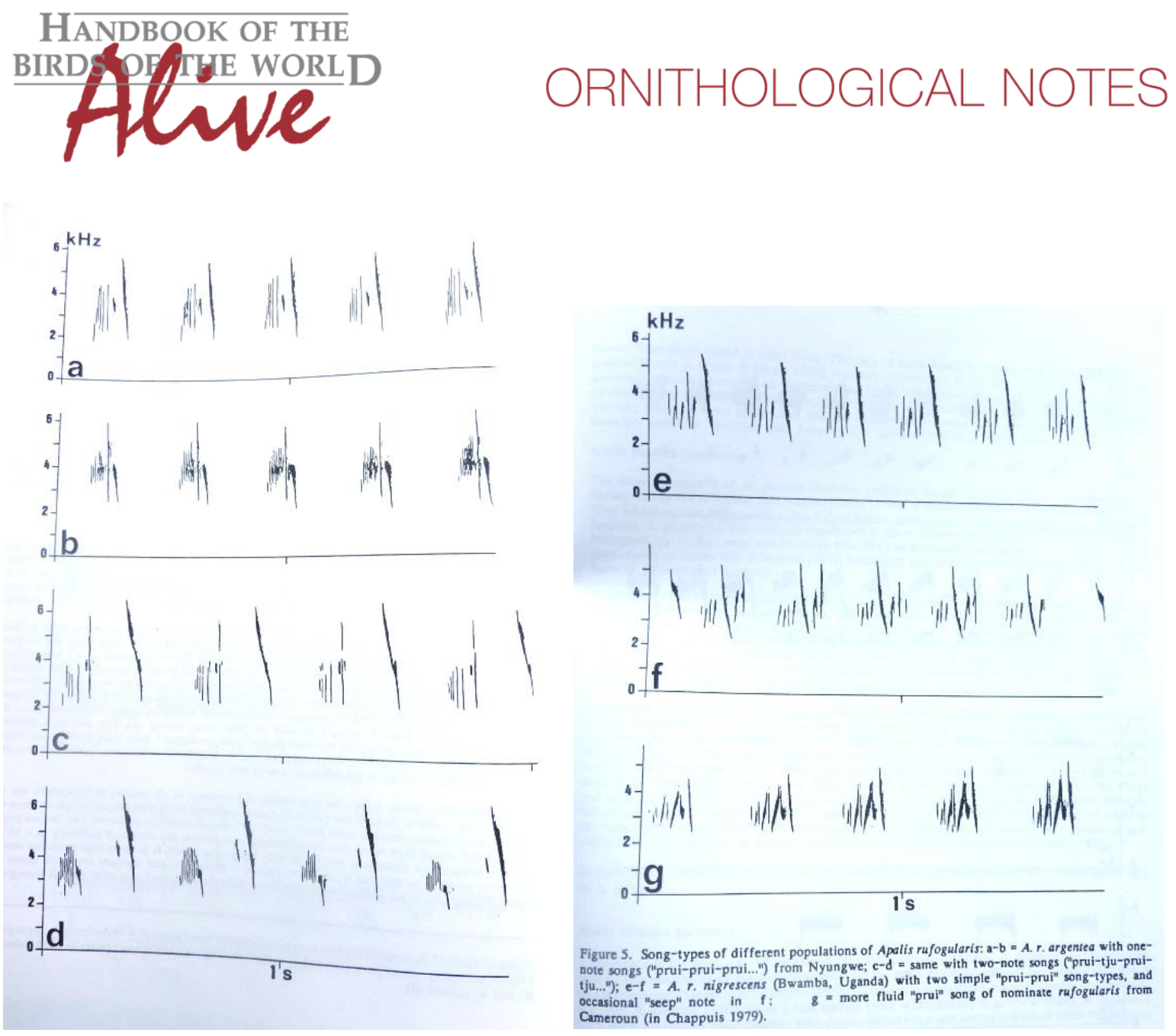

In the same paper playback experiments are also mentioned. While a single case is mentioned of a male reacting clearly to playback of rufogularis, several other cases are also mentioned:

Several other birds tested, some clearly in moult, did not react at all, neither to rufogularis nor to
argentea song. Later in January one pair was clearly interested in its own songs, but not in those of
Cameroun rufogularis; another came down briefly to 7-8 $\mathrm{m}$ in response to playback of its own song,
returned and stayed high when that of rufogularis was played, but chattered excitedly in a 15-m
tall tree, females and immatures joining in with "tjup-tjup" calls. It is likely that reactions would
have been stronger to tapes of Uganda rufogularis - whose dialectal variants are much closer to
argentea songs than those of Cameroun - but those tapes were obtained only after we left Nyungwe.

The least one can say is that it is not a clear-cut case, and caution is needed when interpreting playback experiments, e.g. would the single responsive male have shown a similar reaction to Grey Apalis (counter-singing between different Apalis species has been documented from several localities and for several species)? What about reciprocal experiments; would rufogularis respond to a typical argentea song? Were male or female songs played?

I can confirm, however, that $A$. argentea has a song type uttered in a minority of cases (possibly a female singing alone?), which is nearly identical to $A$. rufogularis. It is clear that the full vocabulary of $A$. argentea is quite extensive, and requires further study. When comparing differences with $A$. rufigularis I will limit myself for the time being to what can be considered homologous songs. 

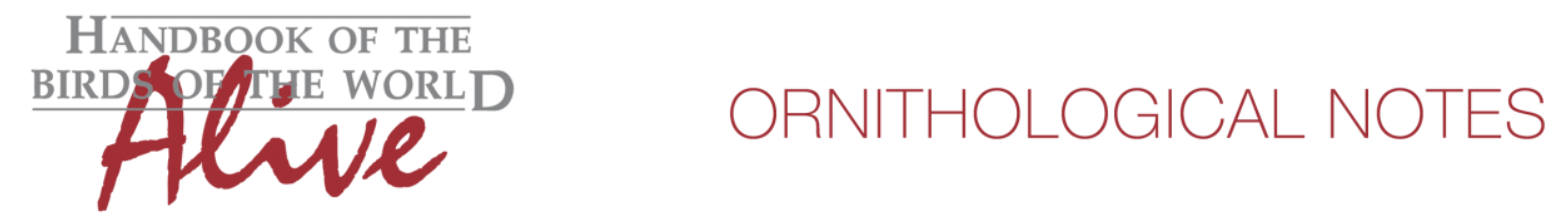

With four recordings of argentea and 12 recordings of eidos, and the additional sonograms depicted in Dowsett-Lemaire \& Dowsett (1990), it gradually becomes clear that this group is vocally quite different from $A$. rufogularis: $A$. argentea delivers its typical song at a slower pace (score 2), has a commonly delivered song type with notes reaching higher max. frequency (score 1-2), higher overall bandwidth (score 1-2), and frequently utters "tsi" notes with a unique note shape (score 1). On the other hand, no obvious differences between argentea and eidos were found.

I thus conclude that the tentative score of 3 given in del Hoyo \& Collar (2016) based on a single recording remains defendable. However, the higher number of available recordings reveals that the full vocabulary of $A$. argentea is quite extensive, and some song types exist that are almost identical to $A$. rufogularis. When considering that song between many Apalis differs only in subtle features, the differences between $A$. argentea and $A$. rufugularis are however substantial.

This note was finalized on 1st November 2018, using sound recordings available online at that time and in private collections. I thank the many sound recordists who made their recordings available on XC and ML, and in particular Michael Mills, David Moyer, Elia Mulungu and Ryan Treves for their recordings of $A$. argentea. Also thanks to Andrew Plumptre and Lincoln Fishpool for bringing up this case and providing inputs, and Guy Kirwan for revising the original text.

\section{References}

Dowsett-Lemaire, F \& Dowsett, R.J. (1990) Zoogeography and taxonomic relationships of the forest birds of the Albertine Rift Afromontane region. Pp. 87-109 in: Dowsett, R.J. (ed.) Enquête Faunistique et Floristique dans la Forêt de Nyungwe, Rwanda. Tauraco Research Report 3. Tauraco Press, Liège.

del Hoyo, J. \& Collar, N. J. (2016) The HBW/BirdLife International Illustrated Checklist of the Birds of the World. Vol. 2. Barcelona: Lynx Edicions.

Mills, M.S.L., Msimanga, A., Reygel, A. \& Louette, M. (2016) Kungwe Apalis Apalis [rufigularis] argentea: a summary. Bull. Afr. Bird Club 23(2): 176-184.

Turner, D.A. and Pearson, D.J. (2015) Systematic and taxonomic issues concerning some East African bird species, notably those where treatment varies between authors. Scopus 34: 123.

Tobias, J.A., Seddon, N., Spottiswoode, C.N., Pilgrim, J.D., Fishpool, L.D.C. \& Collar, N.J. (2010) Quantitative criteria for species delimitation. Ibis 152(4): 724-746. 


\section{Recommended citation}

Boesman, P. (2018). Notes on the vocalizations of Kungwe Apalis (Apalis argentea). HBW Alive Ornithological Note 457. In: Handbook of the Birds of the World Alive. Lynx Edicions, Barcelona. (retrieved from www.hbw.com/node/1527794 on 5 November 2018. 